\title{
Hybridity in Japanese Advertising Discourse
}

\author{
Oana-Maria BIRLEA \\ Babeş-Bolyai University (Cluj-Napoca, Romania) \\ Faculty of Letters \\ Department of Asian Studies \\ oana.birlea@hotmail.com
}

\begin{abstract}
The purpose of this paper is to reveal the impact of cultural exchange on Japanese advertising discourse construction perpetuated through the idea of prestige. This phenomenon can be explained through the concept of mukokuseki (Jap. 無国籍) 'lack of nationality', a term which encompasses the idea of transculturality in Asia. In the context of globalization, erasing the identity or any sort of national mark enhances the absorption and integration of foreign elements and leads to reconsidering aesthetic communication. Japanese advertising discourse is based more on emotional reactions rather than cognitive ones, and this can be noticed through the extensive use of kawaii 'cute' symbolism. Considering that the idea encompassed by the concept of "cute" is present in any culture, and its effects are more or less the same, by freeing it from any cultural or societal restraints (mukokuseki), it becomes an intermediary space where traditional, national elements can overlap foreign ones without damaging the essence of the discourse, but on the contrary. Interculturality and inbetweenness manifests not only at the visual level but also at the linguistic level through hybrid language use: the coexistence of gairaigo (loan words) along wago (words deriving from Japanese) and kango (words deriving from Chinese). According to several studies, gairaigo and wasei-eigo (Japanglish, English words coined in Japan) create a special effect and often serve as euphemisms. Thus, we have selected three Japanese print adverts (displayed between 2000 and 2012) in order to explain the phenomenon by focusing on their sociolinguistic function and their impact on discourse construction. Advertising discourse has surpassed its primary economic function and has come to be a statement of the global world.
\end{abstract}

Keywords: Japanese, advertising discourse, kawaii, cultural semiotics, discourse analysis 


\section{Conceptual framework and methodology}

A culture can be defined by the sum of its discourses if we acknowledge that the analysis of language use in context provides significant insight into the particularities of that culture. The ambiguity of the term "discourse" arises from its polysemantic nature and from the influence of other sciences, consequently leading to a plethora of analysis models. In this case, we will further use the term discourse by referring to a form of social practice, considering that all discourses are rhetorical. In Social Semiotics, Hodge and Kress define text as "a structure of messages or message traces which has a socially ascribed unity" (1988: 6) and discourse as the "social practice in which texts are embedded, while text is the concrete material object produced in discourse" (1988: 6). Also, the concept of genre represents the form of text (article, lecture, scripts, conversation, etc.) according to the rules and implications "which codes the set of practices" (Hodge and Kress 1988: 7). The numerous facets and implications of a media discourse, such as the production, reception, and uses, shall be briefly discussed in this article, the main focus being on its sociocultural functions, with emphasis on the indigenization of foreign elements.

Advertising discourse can be considered a hybrid type due to its complex form provided by interconnections of social, cultural, historical, and economic nature which lead to intertextuality and genre mixing, yet its main purpose is to obtain maximum effect with minimum effort. We use the term "intertextuality" in reference to the relation of one text with other texts (Alfaro 1996). The analysis of language use offers valuable evidence in terms of observing and understanding shifts in cultural values and perceptions of the world. Considering the chameleonic nature of advertising discourse, we propose an interdisciplinary approach taking into account relevant theories in the field of discourse analysis and cultural semiotics. Its forms of manifestation both differ from and resemble others created in a different cultural and social sphere. Besides the influence of other fields of study and types of discourses, another significant factor which contributes to the changes in discourse construction is the influence of global trends which promise to bring a prestigious aura. Thus, in the case of Japanese advertising discourse, the phenomena of adopting and adapting foreign elements played a major role in establishing a new trend, significantly contributing to the image of what is known to be "cool Japan".

Many researchers (Hodge and Kress 1988; Cook 1992, 2002; Fairclough 1989, 1995; Malefyt and Moeran 2003; Tungate 2013) dealing with advertising discourse have approached this subject from a variety of viewpoints (involving marketing, social sciences, linguistics and semiotics, etc.) in search for understanding and explaining the particularities and mechanism of this multimodal discourse. Regardless of the chosen method, the constant element in these studies has been 
its persuasive, manipulative (not necessarily in a pejorative sense), seductive nature. Due to the fact that advertising discourse is perhaps the most complex type of discourse, in which intertextuality plays a major role in discourse construction, we consider that an interdisciplinary approach to discourse analysis is in demand. Our study aims to describe the Japanese society based on Hofstede's cultural dimensions in order to provide an understanding of cultural differences followed by a corpus analysis from a sociolinguistic perspective and to demonstrate that interculturality does not "erase" or disregard traditional values and norms, but, on the contrary, it shows that this particular symbiosis enriches the discourse.

In this article, we shall be focusing on language use and symbolism in printed Japanese social advertisements in order to elaborate the implications of the mukokuseki phenomena and its effects on discourse construction. The data were collected from the official websites of major companies of public transport in Japan (Tokyo Metro and Hankyū Metro), where citizens can find information about past and present campaigns regarding subway etiquette. All analysed posters are available on-line on the official website; moreover, they are actually all displayed in printed form on trains and/or railway station walls. We have selected printed ads for practical purposes because we believe that they can be reproduced entirely, thus making the constituent signs (words and image relationship) easier to track and analyse, whereas in the case of audio-video commercials technical processing is needed.

We consider that this particular type of advertisement offers significant insight into general perceptions of the world which are connected to culture and tradition, and these specificities reflect in discourse construction. Thus, in the case of Japanese manner or etiquette adverts regarding commuter behaviour, we will explore and analyse the constituent signs in relation to kawaii aesthetics reflected both in visual signs and text. Starting from the hypothesis that advertising discourse is constructed in order to persuade the receiver and that objective can be achieved only if there is a common, familiar cultural and social background involved, we will focus on interpreting the underlying meanings in order to see how foreign elements contribute to the changes in Japanese discourse construction.

We will conduct a social semiotic analysis on three non-commercial adverts displayed on trains and subway walls after 2000. Starting from the considerations that a thorough study on advertising discourse needs to interconnect text and context in order to create an integrative research model, we will construct our research by taking into account that words are not to be regarded as isolated elements but as components of the global meaning. By following Hodge and Kress's (1988) model of analysis, our aim is to reveal the mechanism through which foreign elements enrich Japanese advertising discourse. Having as a 
starting point Moeran's statement: "Europe is seen by the Japanese as a repository of 'high culture', and thus of cultural 'depth"” (2003: 106) and that "orientalist and occidentalist images become focal points in a global stylistic continuity and tend thus to be the same, whether they are produced in Japan, Europe or the United States. They both integrate the other and are integrated in the other" (Malefyt and Moeran 2003: 107; emphasis in the original), we shall continue this idea by analysing a series of printed adverts regarding commuters' etiquette. As Yano (2013: 16) presents it, the strategy that accelerated the process of integration and high-speed adaptation (we would add) of foreign trends in Japanese advertising discourse and assured its success overseas was due to the concept of mukokuseki 'lack of nationality' or, more simplified, erasure of Asian origins. It seems that the non-nationalistic appeal is responsible for the popularity of the characters created in this spirit (Iwabuchi 2002: 33). As Iwabuchi (2002) states, the term seems to be used in two ways: "to suggest the mixing of elements of multiple cultural origins, and to imply the erasure of visible ethnic and cultural characteristics" (Iwabuchi 2002: 71). For example, the Japanese anime 'animation' is often referred to as "mukokuseki visual culture", and we consider that this idea can be extrapolated and applied to media as well because in most cases Japanese advertising discourse implies hybrid language use and visuals. The best-known example in this sense is Hello Kitty, the character which, according to its constructed background, is a British "citizen" who can be stated to be responsible for "cute globalization" (Yano 2013). Further elaborating on this idea, we shall conduct an analysis on a selected corpora of relevant printed advertisements in order to elaborate the importance of kawaii in the two-way process: firstly, that of adapting foreign elements in discourse construction according to Japanese principles and values (Japanization) and, secondly, that of integration of Japanese products and values via mukokuseki. We argue that the appeal to gairaigo, wasei-eigo and the extensive use of onomatopoeia, metaphors, and puns in Japanese advertisements are highly influenced by global trends mainly because of the prestige they seem to bring. In several studies (Miller 1998, Hogan 2003, Hatanaka and Pannel 2016), it has been argued that the tendency of using non-traditional Japanese words in favour of borrowed words and/or pseudo-anglicisms is due to their capacity to express the inexpressible, to convey Western qualities, to refer to and bear "different shades of meaning and stylistic values [...] allowing for a greater range of expression" (Rebuck 2002: 55). This tendency of using Japanese wago, Chinese origin kango, and borrowed words has shaped advertising discourse construction. Thus, from the selected adverts, we will list and explain the purpose and effects resulted from choosing one word over another in our attempt to describe the phenomena.

This study will probably benefit researchers who are interested in advertising discourse analysis from a linguistic and cultural semiotics perspective, considering that research on media discourse has increased and the outcomes can 
offer valuable insight into cultural transfers especially in the globalized world in which "cultural diversity and translation problems discourage standardization of advertising message” (Lazovic 2012: 42).

\section{The socio-cultural background}

"Japan is said to be a vociferously assimilating cultural entity: the Japanese modern experience is described in terms of appropriation, domestication, and indigenization of the foreign (predominantly associated with the West) in a way that reinforces an exclusivist notion of Japanese national/cultural identity" (Iwabuchi 2002: 53). In media discourse studies, special attention is to be given to the manifestations of values and ideology in advertising by taking into account differences regarding culture and society. Moreover, after 1900, specialized literature on advertising has "stressed the need for cultural differentiation" (Hofstede 2010: 411). This being the case, we consider that a social-cultural background investigation is highly needed in order to understand discourse construction in a society.

According to Hofstede's cultural dimensions, Japan scores 95 on the "Masculine/Feminine dimension", thus making it one of the most masculine societies in the world. The dichotomy between masculine and feminine type of societies is defined as: "when emotional gender roles are clearly distinct: men are supposed to be assertive, tough and focused on material success, whereas women are supposed to be modest, tender, and concerned with the quality of life" (Hofstede 2010: 140). Another dimension that can bring a clear contribution to understanding discourse construction via Hofstede's scheme refers to collectivistic/individualistic societies. In this case, Japan, with an average score between the two is perceived as collectivistic by the West but as individualist by other Asian neighbours. The implications of this dimension can be resumed in the following: "people behave as members of a family and/or group. Those who do not are rejected by society" (Hofstede 2010: 329). Thus, in the case of Japan, with a score of 46 on the "Individualist/Collectivist dimension" and 95 on the "Masculine dimension", obeying the rules and protecting the decision of the group is an intrinsic rule. Moreover, in collectivistic societies, direct confrontation is to be avoided, and thus the word "no" is rarely used, but instead discourse is constructed on the grounds of "perhaps" and "maybe" in cases where a turndown would follow (Hofstede 2010: 106-107). In high-context languages, such as Japanese, rules and behaviour expectations are deeply rooted in tradition (Hofstede 2010: 219). Hofstede and Mooji (2010: 92) also note about Japan that the most frequent motif used in advertisements is "peacefulness", and, according to the graphics, society is moderately collectivist and guided by wanting to be the 
best. Collectivist societies tend to think in terms of "we" rather than "I" - a power figure is needed (the "Father" figure - the Emperor), harmony must prevail ( $w a$, 和), and communication is implicit, based mostly on context. These differences can be observed in matters of approach, emphasis on certain information, and symbols often incorporated in visual metaphors. For instance, Moeran (1996), Tanaka (2001), and Tungate $(2007,2013)$ address the issue of "uniqueness" in Japanese advertising discourse construction by revealing that even though values differ from one society to another common traits are to be found in its primary purpose: persuasion.

In the case of Japanese advertisements, it seems that yuru-chara (ゆるキャ ラ) 'mascot characters', such as Hello Kitty, Anpanman, Doraemon, etc., play a significant role in persuading the receiver and also in helping with the successful indigenization of foreign elements in Japanese standards. The common point that unifies all the above mentioned characters can be found in the concept of kawaii, most often translated as 'cute', 'adorable' although the Japanese term refers to a much wider sphere. As Kinsella (1995), Yano (2013), and Okazaki and Johnson (2013) note, there is a constant tendency towards embracing and promoting anything based on their kawaii appearance. The very first mentions and descriptions of kawaii seem to be in texts from the Heian period (794-1185), at that time noted as kawayushi. Yet the meaning and principles remained more or less the same: something/someone "lovable", even though certain nuances and other ramifications have arisen in time. The representations of cuteness and loveliness in Japanese advertisements have begun to gain popularity and, more importantly, they have been a bridge between aboriginal and foreign interactions. Yano discusses a "pink globalization - the transnational spread of goods and images labeled kawaii" (2013: 6), and Kinsella (1995: 226) notes that the main principle is that of detachment from Japanese traditional aesthetics and style and moving to foreign style, particularly European or American. As already mentioned, the representations of kawaii cannot be traced in a singular, horizontal line - i.e. in the case of advertising discourse we would find some differences in terms of discourse construction starting from word use, visuals, etc. If we consider commercial or non-commercial advertising slogans or series' titles, the presence of cute slogans is a statement for the popularity of this type of aesthetics and symbolism. For example, the series' title of a manner campaign for the Metropolitan Intercity Railway Company in 2018 is Yasashii yasai [やさし いやさい] 'Friendly/Nice vegetables' in the framework of which from January to December anthropomorphized vegetables had the mission to guide commuters to respect order and common sense rules. In the case of manā kōkoku (マナー広告), a special category of adverts which aim to preserve and promote a healthy social behaviour, the appeal to cute aesthetics, or nowadays known as kawaii aesthetics, emphasis is based on human emotion and basic impulses on the premises that 
the viewer will not sense any sort of constraint, but on the contrary.

In The Languages of Japan, Shibatani (1990: 142) states that there are three lexical layers in Japanese: wago (native Japanese words inherited from Old Japanese), kango (Sino-Japanese vocabulary), and gairaigo (borrowed words). The National Institute for Japanese Language and Linguistics (NINJAL) has added another layer in 1971 that consists of "hybrid" words obtained from mixing the above mentioned three layers. By hybrid words we understand the combination between kanji, Japanese ideograms with katakana syllable used mainly for loan words. Words like haiburiddo kuruma (ハイブリッド車) 'hybrid car', ha burasshi (歯ブラシ) ‘tooth brush', or kissu o suru (キッスをする) ‘to kiss' are examples of this kind. Beside this technique, we encounter a significant number of new words or expressions, such as pauwau shimashō (パウワウしましょう), which do not have an equivalent in another language because they are used as an instrument to convey the motif of that specific campaign. The previously mentioned expression is a slogan specially created for a Shiseidō advertising campaign in 1970, and its purpose was to create the sense of community among women using their products.

\section{Case study - Japanese social adverts (2000-2012)}

There is a two-way process in the case of any advertisement: firstly, for initiated viewers, there is the presupposition that we are familiar with the symbols due to the cultural and social background, and, secondly, we are expected (consciously or not) to engage in semiotic work. In the case of manner advertisements, we can notice that there is a certain repetition in terms of discourse construction due to the fact that expectations regarding social conduct and behaviour do not seem to vary significantly in time. Moreover, these are part of a campaign series, thus giving the impression of continuity by promoting the same ideals under different forms. By being exposed to a series of posters on subway walls, the viewer has the option to "obey" or disregard the notice. As resulted from Hofstede's research, in the case of Japanese society, to act against the group is far less acceptable than in other societies because it would be a direct conflict with wa (和) 'harmony'. Moreover, according to news released on the official website of Japanese transport companies, citizens are constantly involved in the creation process via questionnaires and surveys. Thus, these companies can be more persuasive by knowing the needs and expectations of citizens.

In order to give practical usefulness to the theories and approaches described in the previous chapters, we will discuss the various layers present in Japanese manner adverts. The following printed advertisements were displayed in subways after 2000, informing passengers of the importance of adopting exemplary social conduct and good manners. Perhaps the main difference between these types 
of posters and commercial ones is to be found in their purpose and function. In the case of manner advertisements, there is no economic motif at stake, and therefore the focus is on convincing and changing people's behaviour for the well-being of the community. All selected posters aim at drawing all commuters' attention to actions that might disturb others. The proposed analysis follows the idea that text and context must be perceived as a whole due to their variations in interpretation.

The advertisement illustrated in Figure 1 was displayed in 2004 in Tokyo subways and reveals an interesting facet of Japanese advertising discourse construction. By being displayed in a public place, in this case, subway walls, the advertisement is expected to follow certain rules and policies and, as Hodge and Kress (1988) state, it has a clear impact on the viewer even if it may go unnoticed (1988: 9).

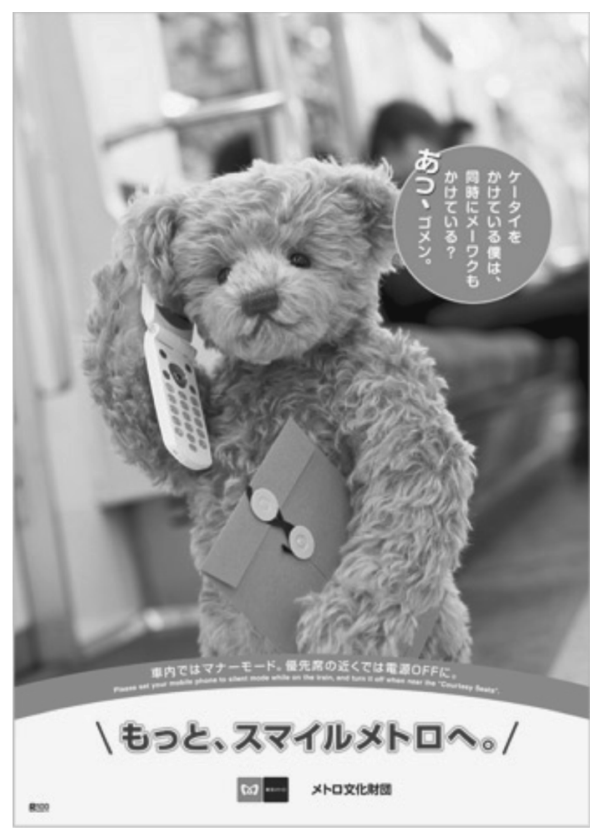

Figure 1. Tokyo Metro campaign - Motto sumairu metoro he (もっとスマイルメトロヘ), 2004

The campaign consists of a series of printed advertisements entitled Motto, sumairu metoro he (もっと、スマイルメトロヘ) 'Towards a more smiley metro', and the text in the original is: Keitai o kaketeiru boku wa douji ni meiwaku mo kaketeiru? A, gomen. - (ケータイをかけている僕は同時にメーワクもかけてい る?あっ、ゴメン。), which would translate as "While I'm making calls I'm also bothering you? Oh, sorry." The wordplay is created by the use of two phonogram words. The verb kaketeiru - which has over twenty meanings -, if not attributed 
to a specific context or transposed in kanji, it is a method of drawing attention to the action. The meaning of the first verb is "make a call", whilst the second one is "to cause", thus having two completely different meanings. Unfortunately, the wordplay is lost in the process of translation because there is no option of using the same verb in both cases. This first advertisement is constructed on a series of techniques such as appealing to a focal point in order to draw the receiver's attention, symbolism by making a direct link to a deeper meaning, direct gaze, and others. Our focus is not directly concerned with offering a detailed description of advertising techniques, but in order to create a more complex analysis we shall mention some elements which are important in understanding certain construction choices.

The original picture focuses on a small, kawaii teddy bear, perhaps the global symbol of childhood and need of affection. This anthropomorphized bear along with a Japanese text are direct signs of transculturation and cultural mix. However, it is important to observe that the presence of a foreign element does not contradict or obstruct Japanese beliefs or norms but comes to reinforce the discourse based on the values it carries. The previously mentioned focal point leads the viewer to decode a specific message and also helps them in creating a realistic situation. In this case, through this technique, Teddy, the bear, is transposed in a normal citizen's life who confronts with an unpleasant situation while commuting.

The text in the right upper part of the advert is restricted to a delimited space, in a circle, thus reminding us of comic books and making it more accessible to the viewer. It basically indicates that Teddy is having a moment of revelation and realizes that he is disturbing other commuters by talking on the phone. The text size also differs in order to emphasize and draw attention and, in this case, the exclamation word A! (あっ ! ) 'Oh!' is significantly larger than the rest of the text and also exceeds the speech bubble. In the lower part of the advertisement, there is a small explanatory note using formal Japanese and English expression and requesting commuters to switch their phones on silent mode while commuting. Therefore, we have the same idea of refraining from talking on the phone communicated through two different types of speech: informal and formal. The campaign slogan is positioned right under this explanatory note and follows the same casual note. The presence of both wago and kango along gairaigo (sumairu 'smile', metoro 'metro') is very common in advertising due to its capacity to suggest novelty and exoticism. The numerous synonyms in Japanese can be explained by their usage considering the context. There are other equivalents in kanji for the word sumairu (スマイ ル) 'smile' - for example, hohoemi (微笑み) -, but the borrowed word is preferred in this particular context because the intention is to create a "cosmopolitan mood" (Tomoda 2005: 29), and words of Japanese/Chinese origin do not bear the same connotation. Besides their capacity to enrich vocabulary, words written in 
katakana draw the receiver's attention, and thus sumairu and metoro are preferred instead of hohoemi and chikatetsu written in kanji.

The analysis of text and visual signs must be correlated with that of culture and social background in order to fully comprehend its use and purpose in that specific context. "Cartoon characters [...] literally add characters to their lifelessness" (Kinsella 1995: 227). Thus, with the presence of the anthropomorphized teddy bear along its kawaii in the advertisement in Figure 1, the cute discourse engages the viewer in a relaxed atmosphere and suggests paying attention to other passengers so that in the end they should not act like "the bear". Moreover, the appeal to yuru-chara and casual style as an instrument for drawing passengers' attention helps avoiding "direct confrontation" with the viewer by distraction. By this, we refer to the fact that many Japanese advertisements target people's basic human reactions, such as affection or tenderness, to that service, product, or idea through kawaii aesthetics and symbolism due to the fact that there is a certain intimacy created between the viewer and that "cute, vulnerable, adorable" character used. The teddy bear is considered to be a stereotypical toy in the West, but in this case the stuffed animal is anthropomorphized into an employee, a salary man (サラリーマン, sararīman), possessing a mobile phone and an envelope suggesting everyday city life.

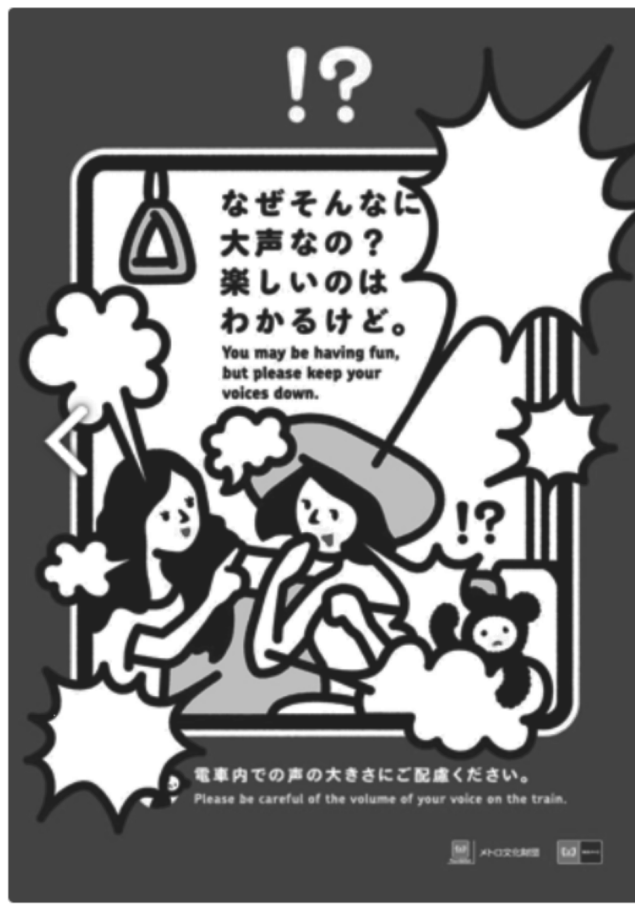

Figure 2. Tokyo Metro campaign「なぜ！？」,2012 
Continuing in the same note, the advertisement in Figure 2 is part of a campaign developed for Tokyo Metro in 2012 and aims to promote etiquette among commuters by offering counterexamples. The title of the campaign is Naze!? (なぜ! ?) 'Why!?’, and the viewer is involved from the very beginning by using this question word (considered an adverb in Japanese). In Japanese, there are several other equivalents, such as dōshite or nande, and the difference consists in their formal/neutral/informal style and usage depending on context. The interrogative naze is the most formal among these three, and it conveys the idea more directly. It is usually used in writing rather than in speech. From this first-hand explanation, we can understand the reason for choosing naze instead of the other two: it is used in writing, and it wants to draw attention by stating a point of view in a more direct manner; moreover, it expects immediate involvement from the viewer. In writing, interrogatives give the sensation of a real conversation (Hodge and Kress 1988: 126), and also by concentrating on the main idea around interrogatives it creates a relationship with the recipient by leaving the impression of a pending answer.

By looking at the previously analysed advertisement, we notice that there is a recurrent element present: the teddy bear. Even though the representation in the first advert differs completely from the one in Figure 2, the bear is again the main character by being present in all posters of this campaign. The role played by the anthropomorphized bear is to draw commuters' attention, thus becoming a kawaii metro security guard. As previously mentioned, the appeal to kawaii signs is a means to persuade the receiver and to indigenize foreign signs. By their representation, the bear and the other two female figures cannot be indisputably linked to a certain culture or society. Mukokuseki neutralization (erasure of nationality) is used in order to generalize the situation and to deliberately omit its ties with a specific culture or society or, as Yano notes, "what is interpreted as 'without nationality' is actually very much imbued with Euro-American culture or race" (2013: 6).

Along with the sketches of the two young women, the presence of several speech bubbles gives the impression of a comic book. The simplicity in style (the appeal to only three colours) is counterbalanced by the abundance of text in the upper part of the advert. The focus is on the two female figures surrounded by these speech bubbles suggesting an intensive dialogue. Only after a second look can we notice the presence of a small kawaii bear in the right corner, who seems overwhelmed by the situation. As mentioned, this character is the constant element of the series, and its role is to impersonate a real person, a commuter dealing with the presented issue. Also the presence of the question marks above the character links it to the main idea of the campaign: imperatively asking for a reason to disregard other fellow passengers.

The text of the advertisement is bilingual (Japanese and English) in order to address both foreigners and Japanese citizens. In the upper side of the 
advertisement, in black letters, we have the connection between the question marks and the bear's thoughts: Naze sonnani ogoe nano? Tanoshii no wa wakaru kedo (なぜそんなに大声なの? 楽しいのはわかるけど。) 'You may be having fun, but please, keep your voices down'. The English translation conveys the intended message, but the subtle irony present in the Japanese version is lost. One possible argument for choosing to reformulate might be due to the differences in discourse construction. To be more specific, the English version seems to be adapted in order to appeal to foreigners who might be unfamiliar with the subtleties of this culture. The word "please" does not appear in the Japanese version nor does it imply any kind of direct suggestion like the English one. A more accurate translation that could imply the irony and a subtle sarcasm would be: "Why so loud? I/We understand you're having fun, but still...”. Perhaps this need to add the word "please" is a reflection of Japanese interpreting Euro-American discourse construction. In this advertisement, foreign influence is reflected more through visual signs rather than text which is consistent in using solely wago and kango words. The presence of the question and exclamation marks (mostly used in creative writing and manga) is also a sign of linguistic contact and borrowing from Western languages because in Japanese no particular symbol is used to mark interrogative/exclamatory sentences.

The last example (Figure 3) is a very recent advertisement displayed in 2018, part of a large campaign started in 2015, according to the official website of Hankyu Corporation. Again, the main topic is promoting etiquette and good manners as clearly stated in the series' title: Good manā Good raifu (Good マナ — Good ライフ) ‘Good manners, Good life'. This poster was also displayed in Hankyū stations and trains, and it focused on a specific rule that must be respected: keeping quiet while travelling on the train. Through this series, several types of possible events have been described in various advertisements since 2015, but the one represented in Figure 3 is part of a special edition series in collaboration with Peanuts Worldwide, an American company who operates the Peanuts comic strip, DVD, and TV shows.

The side story is available in Japanese on the official website of Hankyū Corporation, and it explains the idea behind the advertisement. Snoopy, the beloved American character, is watching over endless dreams with the eyes of a grown-up. Charlie Brown's sister told the other two about her dream of becoming an astronaut, and, even though Charlie and Snoopy were amazed by this and noticed a big change in her, they did not talk aloud because they are considerate of others. Thus, we draw a simple conclusion: be like Snoopy and Charlie, do not talk aloud while commuting! This simple idea of respecting others and paying attention to etiquette is conveyed through well-known and loved American cartoon characters but in a totally different social and cultural context. The same idea is applied in the case of kawaii Hello Kitty, who is responsible for the so- 
called "pink globalization", as Yano (2013) puts it. Yet in this case it is the reverse process: a foreign element is "indigenized" due to its neutral dimension, adding more nuances to the Japanese text used.

The image of the three characters used in this advert seems directly borrowed from the original American show. Given its long history on the market, associating Peanuts gang with manners and etiquette among commuters seems to be a successful method. The presence of these particular cartoons come to sustain the idea that mukokuseki is not really culturally and socially transparent because these are one of the first American cartoons thus suggesting American values and prestige.

In this case, we have a mix of English words, kango, wago, and gairaigo, and this makes the advertisement a complex one from several points of view. First, in the left upper side of the poster, we have the following text in English: 'PEANUTS with HANKYU Everyday!', and exactly parallel to it, on the right side, there is the Hankyū logo. By writing the two words in capital letters, an immediate connection between the two companies is suggested. One is responsible for amusing people and the other one for offering good-quality public transport. Thus, this unexpected collaboration is meant to show a more casual, relaxed, kawaii facet of the transportation company and by this to persuade the viewer to adopt the same attitude as the beloved American characters.

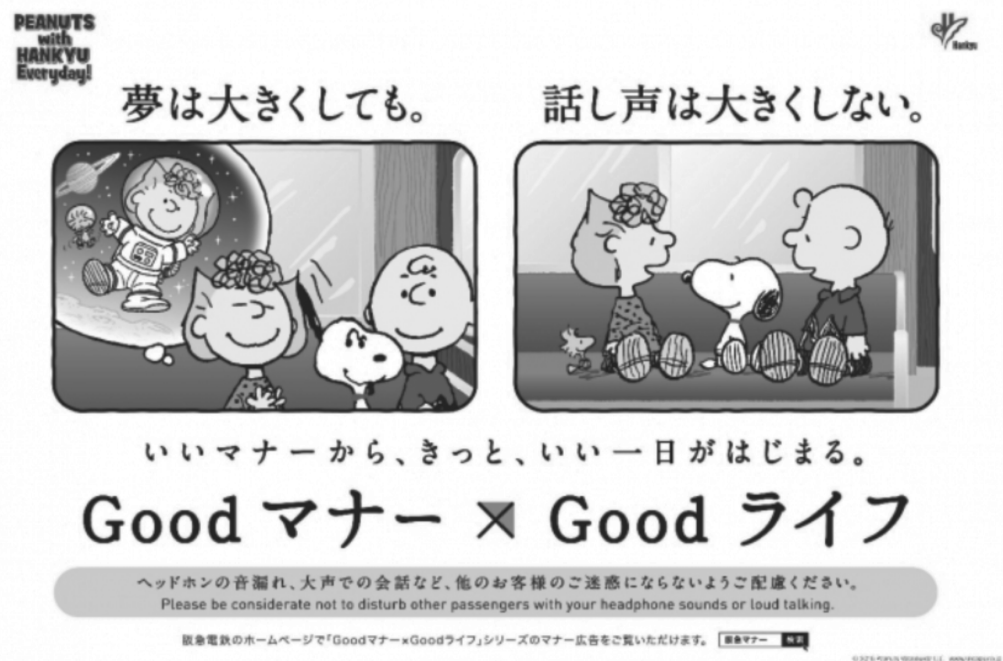

Figure 3. Hankyū (Good マナー Good ライフ) campaign in collaboration with "PEANUTS", 2018

Interculturality and in-betweenness lead to hybrid language use, and visual signs in advertising discourse contribute to the originality of the discourse 
through unexpected associations, intertextuality, and allusions. The motto of the poster is written entirely in Japanese without translation: Yume wa ókiiku shitemo. Hanashigoe wa ōkiku shinai. (夢は大きくしても。話し声は大きくし ない。). There is a tendency towards not translating mottos in advertisements (as seen from the analysis of the above mentioned three posters). Only specific instructions are translated, and the humorous or sarcastic tone is lost in the process. A literal translation of the text would be: 'Even though you dream big. Do not speak loudly.' However, this translation would not make much sense for a foreigner in Japan. The fact that only instructions referring to commuters' conduct is translated in an objective tone ("Please be considerate not to...") is because the implications of the Japanese discourse would not be the same in the case of a foreign receiver, unfamiliar with the nuances, and thus it would not produce the same effect. Moreover, in the West, most adverts of this type are constructed on imperative forms (ex: "Do not...!") in an objective manner; thus, in this case too, only the informative part is translated.

Similarly, the use of the punctuation mark between the two phrases is quite unusual in common speech because it is a concessive clause constructed with temo (ても) 'even though'. The presence of the punctuation mark is meant to separate the actions: dreaming and the consequence of telling others about it. Naturally, the exemplified action can be interpreted in a more general sense, but it was chosen in order to fit the characters' behaviour. Immediately after the two images, we have an explanation note of the motto in Japanese: Ii manā kara, kitto, ii ichinichi ga hajimaru (いいマナーから、きっと、いいー日がはじまる。) ‘A good day starts with good manners'. This phrase also lacks the English translation; therefore, it is limited to Japanese speakers. Another interesting aspect is that the two adjectives, "ii" (Jap. "good") and "good", encompass different values even though they are word pairs. In the motto, the English word is preferred, whilst above the Japanese word is used. As noted by Haarmann (1986), these words are preferred because they are a mark of modernity and because they are fashionable. Even though Japan is a monolingual country, the frequency of foreign words in advertisements and in daily speech is impressive. It seems that this phenomenon is related to "the attitude Japanese have toward foreign cultures in general" (Haarmann 1986: 212), that is, gairaigo words "display a unique configuration of prestige symbols which are applied by the Japanese themselves for the purposes of ethnocultural stereotyping" (Haarmann 1986: 260). As seen in the previously analysed posters, only the general rule or request is bilingual, and it is constructed in formal speech as opposed to the narrative part (characters' ideas, monologue, etc.), which is entirely in colloquial Japanese. The analysis of these adverts reveal the use of emblematic American comic figures along loan words and wago and kango as indicators of acculturation. 


\section{Conclusions}

Interculturality and in-betweenness have increased in the era of globalization, and their effects can be seen in various forms especially in discourse construction. In the case of advertising, we consider that this exchange process and borrowings can enrich the discourse if adapted to a specific socio-cultural space. In the case of Japanese manner advertisements, we notice a tendency in internalizing foreign elements through the use of kawaii aesthetics. Therefore, by bringing in EuroAmerican symbols on the premise of prestige and by rethinking them in order to fit Japanese culture and values, the viewer is persuaded by equating certain behaviours with an idealized social life that comes to support the most important cultural concept, $w a$ (和) 'group harmony'.

The relationship between language, society, and culture in the context of globalization can be analysed in many types of discourse, but we consider that the analysis of advertising discourse can reveal significant differences in worldview through discourse construction. Understanding cultural keywords grants permission to cultural insights in a society. Moreover, the results of discourse analysis with focus on affect words provide the necessary tools to discover existing patterns in discourse construction and thus to achieve a more comprehensive approach to differences in languages and cultures. In the case of Japan, kawaii, an adjective standing for "cute", "adorable", "vulnerable", and "innocent", has rapidly extended its reach by becoming overwhelmingly present in various shapes and forms in everyday life. The evolution of kawaii as a social and cultural artefact along the indigenization of foreign elements has greatly contributed to the changes in discourse construction, wherefore a thorough analysis of this concept is of significant importance especially in the context of globalization. The conducted analysis has revealed that gairaigo words play an important role in Japanese advertising discourse because of their capacity to refer to a wide range of attitudes and behaviours which are perceived as different from the traditional ones, thus encompassing a somehow new set of values attributed to the West. Also, the juxtaposition of English words with Japanese wago and/ or kango creates the perfect environment in which tradition can meet trends, modernity, and innovation. Adverts represented in figures 1 and 3 are examples of hybridity manifested not only through language use and visual signs but also through symbols, whilst the example in Figure 2 is a case in which the appeal to mukokuseki is an indicator of acculturation (different from assimilation). Kawaii symbols in adverts have the role to persuade the receiver, and the presence of Japanese words of different origins contribute to the creation of a cosmopolitan world for the Japanese receiver. Even though gairaigo words are written in katakana syllable, they are perceived as carrying some other symbolic load. 
As illustrated in this paper, interculturality and in-betweenness in Japanese advertising discourse are visible through the co-existence of kawaii aesthetics along Euro-American characters and hybrid language use. Through the analysis conveyed, we conclude that advertising discourse, regardless of its type, has become a statement of interculturality, and in the present case the use of affect words along with foreign elements represents an instrument for persuading the viewer by appealing to specific words and visuals correlated with the idea of prestige.

\section{References}

Alfaro-Martinez, Maria Jesus. 1996. Intertextuality: Origins and development of the concept. Atlantis 18(1/2): 268-285.

Cook, Guy. 2001 [1992]. The Discourse of Advertising. London: Routledge.

Fairclough, Norman. 1989. Language and Power. London: Longman.

-1995. Critical Discourse Analysis: The Critical Study of Language. London: Longman.

Haarmann, Harald. 1986. Language in Ethnicity: A View of Basic Ecological Relations. Berlin, New York, and Amsterdam: Mouton de Gruyter.

Hatanaka, Mariko-Justin Pannel. 2016. English loanwords and made-in-Japan English in Japanese. Hawaii Pacific University. TESOL Working Paper Series 14: 14-29.

Hodge, Robert-Gunther Kress. 1988. Social Semiotics. New York: Cornell University Press.

Hofstede, Gert Jan-Michael Minkov Hofstede. 2010. Cultures and Organizations: Software of the Mind. New York: McGraw: Hill.

Hogan, Jackie. 2003. The social significance of English usage in Japan. Japanese Studies 23: 43-58.

Iwabuchi, Koichi. 2002. Recentering Globalization: Popular Culture and Japanese Transnationalism. London: Duke University Press.

Iwabuchi, Koichi-Eva Tsai-Chris Berry, eds. 2016. Routledge Handbook of East Asian Popular Culture. New York: Routledge.

Kinsella, Sharon. 1995. Cuties in Japan. In Brian Moeran-Lise Skov. Women, Media and Consumption in Japan, 220-254. London: Curzon Press.

Lazovic, Vesna. 2012. Content analysis of advertisements in different cultures. Elope 9: 39-51.

Malefyt, Timothy de Waal-Brian Moeran, eds. 2003. Advertising Cultures. Oxford: Berg.

Miller, L. 1998. Wasei eigo: English "loanwords" coined in Japan. Jane H. Hill-P. J. Mistry-Lyle Campbell (eds), The Life of Language: Papers in Linguistics in 
Honor of William Bright, 123-139. Berlin/New York/Amsterdam: Mouton de Gruyter.

Moeran, Brian. 1996. A Japanese Advertising Agency. An Anthropology of Media and Marketing. London: Curzon.

Mooij, Marieke K.-Geert Hofstede. 2010. The Hofstede model applications to global branding and advertising strategy and research. International Journal of Advertising 29: 85-110.

Okazaki, Geoff, Johnson. 2013. Kawaii!: Japan's Culture of Cute. London: Prestel. Shibatani, Masayoshi. 1995. The Languages of Japan. Cambridge: Cambridge University Press.

Tomoda, Takako. 2005. The Loanword (Gairaigo) Influx into the Japanese Language: Contemporary Perceptions and Responses. PhD Thesis. School of Sociology, University of New South Wales.

Tanaka, Keiko. 2001 [1994]. Advertising Language. A Pragmatic Approach to Advertisements in Britain and Japan. London: Routledge.

Tungate, Mark. 2013 [2007]. Adland: A Global History of Advertising. London: Kogan Page Limited.

Yano, Christine, R. 2013. Pink Globalization: Hello Kitty’s Trek across the Pacific. London: Duke University Press.

\section{Web sources}

www.hankyu.co.jp/files/upload/pdf/180330manners.pdf (Last accessed: 15 March 2019)

https://g2015graman.top/archives/9062.html (Last accessed: 15 March 2019) https://www.bloomberg.com/research/stocks/private/snapshot. asp?privcapid=129342191 (Last accessed: 20 March 2019) http://www.metrocf.or.jp/manners/poster.html (Last accessed: 20 March 2019) https://www.lostateminor.com/2010/08/17/tokyo-subway-manner-posters (Last accessed: 20 March 2019)

http://pinktentacle.com/2010/08/vintage-tokyo-subway-manner-posters (Last accessed: 20 March 2019)

https://www.academia.edu/14274854/Advertising_in_Japan (Last accessed: 20 March 2019)

https://www.charabiz.com/article_list.php?category=2 (Last accessed: 20 March 2019) 